\title{
A longa e tortuosa trajetória da Autonomia Universitária no Brasil : entrevista com Márcia Bassetto Paes
}

丩 1 árcia Bassetto Paes possui uma história de vida e luta vinculada à ideia de presa em 1977 por distribuir panfletos nas portas de fábricas do ABC paulista. Assim como outros militantes de esquerda, encarou os poróes da ditadura, foi torturada. Sentiu na pele o peso da censura, da repressão à livre expressão do pensamento e à autonomia do cidadão. A ditadura interrompeu sua formação como historiadora, mas regressaria à universidade outras tantas vezes, formando-se em Marketing, Letras e Licenciatura (Português). Atualmente é doutoranda na Faculdade de Filosofia, Letras e Ciências Humanas da Universidade de São Paulo (FFLCH-USP), pesquisando a bistória dessa mesma universidade nos tempos da ditadura. Nesta entrevista, conversaremos com a doutoranda Márcia Bassetto sobre a longa e tortuosa trajetória da autonomia universitária no Brasil.

Entrevista realizada por Dirceu Franco Ferreira, doutorando do Programa de Pós-Graduação em História Econômica da Universidade de São Paulo (USP) e membro do Conselho Editorial da Revista Angelus Novus (RAN).

Submissão

$26 / 07 / 2020$

Publicação

$02 / 09 / 2020$ 


\section{REVISTA ANGELUS NOVUS}

Você iniciou a graduação em História nos anos 1970 e agora está de volta ao departamento de História da USP para realizar seu doutoramento. Como você descreveria esses dois contextos, levando em consideração o fato de que no primeiro não havia autonomia universitária?

\section{MÁRCIA BASSETTO PAES}

Entrei para o Departamento de História em 1976, e retornei à USP em 2010 para fazer Letras. Nessa volta, fui convidada pela Prof. Dra. Janice Theodoro da Silva para integrar a equipe de pesquisadores da Comissão da Verdade da USP. Graças a esse trabalho, bastante importante no âmbito da Universidade de São Paulo, pude desenvolver o meu projeto de doutorado, que é exatamente a reconstituição de um acervo documental produzido por um órgão de informação que atuava dentro da Universidade de São Paulo - a AESI (Assessoria Especial de Segurança e Informação), ligada ao Serviço Nacional de Informações (SNI). É interessante pensar nos dois contextos, mas é necessário, de antemão, estarmos de acordo com a definição de autonomia universitária. A Constituição de 1988 estabeleceu importantes marcos para essa definição. Explicita que as universidades têm liberdade para construir sua identidade e assumir seu papel social no Estado democrático de direito. Segundo o Art. 207, "as universidades gozam de autonomia didático-científica, administrativa e de gestão financeira e patrimonial, e obedecerão ao princípio de indissociabilidade entre ensino, pesquisa e extensão". É uma definição que pode ser usada para equacionarmos esses dois contextos. Em meados dos anos I970, um dos fantasmas que pairava sobre as universidades públicas era a implantação do ensino pago. Essa pauta mobilizou durante muito tempo boa parte dos estudantes e foi o caminho inicial para a reconstrução das entidades representativas destruídas pela ditadura civil-militar.

Hoje, nos vemos ainda, ironicamente, não só às voltas com a penúria financeira, mas também quanto a sua laicidade e à liberdade de pensamento. Temos vários exemplos de ocorrências bem recentes para serem pinçadas. As ocupações em 2013, com destaque para o episódio da UnB; a crise vivida com a falta de repasse de verbas e o consequente fechamento da Universidade do Estado do Rio de Janeiro (UERJ) por vários meses, com prejuízo para toda a comunidade acadêmica, para o desenvolvimento

$86 \bullet$ ano XI, n. I6, $2020 \bullet$ ISSN 2179-5487 
das pesquisas e, ainda, para a população que deixou de ser atendida em suas unidades de saúde. Somam-se a falta de recursos, as ingerências no livre-pensar acadêmico. Às vésperas do segundo turno das eleições presidenciais, várias universidades públicas sofreram ataques por parte de fiscais da Justiça Eleitoral e da polícia, a fim de reprimir manifestações estudantis antifascistas. Uma violação clara à liberdade de expressão e à autonomia universitária. E, claro, não podemos esquecer a falsa polêmica da "Escola sem partido", amplificada sob o governo de Jair Bolsonaro.

Bolsonaro tentou, ainda, passar a medida provisória que impunha várias restrições à autonomia universitária. Dentre elas pesos diferentes para os integrantes das comunidades acadêmicas, proibição da reeleição de reitores e de professor que houvesse substituído o reitor por mais de um ano no mandato anterior, além de que os candidatos enquadrados na Lei da Ficha Limpa não poderiam concorrer.

O Ministério da Educação, e todos os seus reveses, são a constatação de toda a crise que as universidades sofrem hoje.

\section{RAN}

De que maneira a questão da autonomia universitária era discutida nos anos 1970, na Universidade de São Paulo?

\section{MBP}

Há 45 anos os recursos eram exíguos. Havia descaso com a formação dos professores; os exames vestibulares seletivos controlavam a entrada nos cursos, elitizando as escolas; alunos e jovens professores tinham pouca ou nenhuma voz ativa nos assuntos universitários; as universidades dividiam-se em escolas isoladas, departamentos estanques que não permitiam o aproveitamento racional de seus recursos e impediam a formação interdisciplinar. A Universidade precisava urgentemente ser aberta, ampliada, flexibilizada, enriquecida, valorizada, democratizada. Naquela altura, as comunidades acadêmicas levantavam a bandeira da Reforma Universitária. Havia ainda a reivindicação da volta dos professores e pesquisadores atingidos pelo AI-s e a revogação do Decreto-Lei no 477. Hoje, lamentavelmente, além de muitos problemas dessas pautas não terem sido resolvidos, temos outra lista sensivelmente ampliada. 


\section{REVISTA ANGELUS NOVUS}

\section{RAN}

Você se vinculou à Liga Operária e à Convergência Socialista. Como você avalia a contribuição dessas organizações para o debate sobre a autonomia universitária e liberdade de pensamento no Brasil da transição da ditadura à democracia?

\section{MBP}

A Convergência Socialista foi criada pela Liga Operária. Foi uma política absolutamente acertada daquele pequeno grupo de trotskistas ao vislumbrar a possibilidade de abertura em consequência das mobilizações contra a ditadura civilmilitar. Seu principal objetivo era reunir os socialistas num movimento massivo para participar aberta e legalmente da vida política brasileira. Conseguiu o apoio de intelectuais, artistas, dentre eles Mário Pedrosa, além de ampliar a tímida penetração que já havia iniciado entre a classe trabalhadora colocando claramente o socialismo como horizonte de uma sociedade mais justa e igualitária. Acredito que alguns números revelam a importância no processo de abertura que se inaugurava. A primeira convenção nacional do Movimento Convergência Socialista, após uma ampla preparação prévia de discussões, conseguiu reunir mais de 300 delegados representando oito estados. Contou, ainda, com cerca de I.20o pessoas.

\section{RAN}

Na capa da edição n. 16 da Revista Angelus Novus publicamos uma foto das mobilizações que tomaram as ruas do Brasil em 1977, com forte apelo às liberdades democráticas. Como sua trajetória se vincula a esse momento e como você interpreta a questão da autonomia universitária como parte das liberdades democráticas no contexto do Estado de Direito?

\section{MBP}

Pois é, a foto me chamou a atenção porque trata-se de uma das manifestações, acredito que a maior delas, ocorrida em 5 de maio de 1977, realizada pela minha libertação e de outros companheiros que foram presos comigo: Anita Maria Fabbri, da História/USP, Celso Brambilla, operário da Mercedes-Benz, José Maria de Almeida e

$88 \cdot$ ano XI, n. I6, $2020 \cdot$ ISSN 2179-5487 
Ademir Marino, operários, Cláudio Lúcio Gravina, da PUC e Fernando Lopes, militante do MEP (Movimento de Expansão do Proletariado), não me recordo em que setor Fernando atuava. Havia uma reivindicação pontual e uma geral. As palavras de ordem eram "Libertem nossos presos", "Por Liberdades Democráticas", "Pelo Estado de Direito”. Eu, Celso, Zé Maria de Almeida havíamos sido presos na madrugada de 28 de abril enquanto pendurávamos alguns panfletos referentes ao primeiro de maio, em portas de algumas fábricas do $\mathrm{ABC}$. Naquela altura, eu havia trancado o curso de História e trabalhava em uma fábrica metalúrgica em São Bernardo. Os dirigentes da Liga Operária apostavam na reorganização dos trabalhadores e viam o polo metalúrgico de São Bernardo como a vanguarda desse processo que poderia se iniciar. Naquela altura, os sindicatos eram totalmente controlados por pelegos, as oposiçóes atuavam na clandestinidade. Havia um operário, o Luís Inácio da Silva, que começava a se distinguir como uma futura liderança. Os nossos panfletos colocavam o primeiro de maio no marco da luta dos trabalhadores e não uma efeméride para festas, como queriam os pelegos. Reivindicávamos aumento de salários e nos posicionávamos contra as políticas econômicas implementadas pelo regime militar. Isso foi muito importante porque nós não nos confundíamos com as propostas da luta armada, por exemplo, última manifestação absolutamente derrotada das lideranças de esquerda. Por outro lado, sensibilizávamos parcela importante de trabalhadores já bastante desgastados com a política econômica. Dois dias após a nossa prisão, os militantes da Liga Operária conseguiram levar a uma assembleia no auditório da História cinco operários, meus companheiros na oposição. Um deles, inclusive, uma velha liderança do setor químico. Eles, muito emocionados, pediram aos estudantes que se mobilizassem pela nossa libertação. Foi um episódio bastante emocionante e serviu como estopim para os estudantes saírem às ruas. Após a assembleia nos Departamentos de História e Geografia, seguiram-se outras dentro da USP, da PUC, Unicamp e se alastraram para várias outras universidades de outros estados.

As mobilizações de 1977 são um momento ímpar na história do movimento estudantil e compõem um recorte bastante interessante para pesquisa. Acredito que tenha sido um ano recorde de prisões estudantis. $\mathrm{O}$ documentário $\mathrm{O}$ apito da panela de pressão é um importante registro dessas mobilizações. Foi filmado por estudantes anônimos (não usávamos nossos nomes à época, por conta da perseguição) que assinavam como grupo Alegria e distribuído pelos DCEs recém-fundados da USP e da PUC.

I Para mais informações, acessar o link: «https://www.youtube.com/watch?v=lEPfssOenJ4». 


\section{RAN}

A partir de sua trajetória na militância estudantil e como pessoa sensível à formação universitária das novas gerações de lideranças, como você compreende o atual momento da autonomia universitária no Brasil?

\section{MBP}

Estamos, na verdade, vivendo o ápice de um processo que começou lá atrás, com o neoliberalismo. Hoje, não só não conquistamos a autonomia administrativa, reivindicação antiga, como sofremos com o corte sistemático de verbas das fundações que fomentam a pesquisa nas universidades. O financiamento da pesquisa no Brasil se dá por meio de diferentes sistemas e instituições ligadas direta ou indiretamente aos ministérios. CNPq, Finep, CAPES, FNDCT, BNDES são as principais delas, além das agências estaduais que constituem as FAPs - Fundações Estaduais de Amparo à Pesquisa agrupadas no CONFAP. Estas instituições estão cortando violentamente o financiamento de pesquisa no Brasil. O fim do projeto Ciência sem Fronteiras, composto pelos Ministérios da Ciência, Tecnologia e Inovação (MCTI) e Ministério da Educação (MEC), por meio de suas respectivas instituições de fomento - CNPq e Capes -, e Secretarias de Ensino Superior e de Ensino Tecnológico do MEC, representou um corte violento em vários projetos de pesquisa. Nem vou entrar no âmbito particular das Ciências Humanas que nessa cadeia alimentar dos financiamentos ocupa o patamar mais baixo da pirâmide e é, historicamente, prejudicada.

Hoje, as principais agências de financiamento da pesquisa - CNPq e CAPES enfrentam problemas com a redução de orçamento. Há também leis de Incentivo Fiscal e Fomento à Inovação, financiamentos empresariais que constituem o outro lado da moeda no quesito autonomia financeira. Cito o exemplo da entrada do curso de Coreano na Letras da USP. Quem percorrer o corredor das salas das secretarias dos cursos da Letras irá se deparar, na porta da sala de Coreano, com um cartazete grudado ostentando os logotipos da LG e da Samsung. Ou seja, com o apoio dessas empresas, que não sabemos muito bem como se dá, foi implementado um curso para os técnicos de empresas coreanas instaladas no Brasil. Enquanto isso, outros cursos do Departamento de línguas orientais e de importância ímpar, como russo, estão à míngua, sem professores e sem perspectiva de sobrevivência. Os partidários do desenvolvimentismo a qualquer preço são os entusiastas dessas parcerias.

$90 \cdot$ ano XI, n. 16, $2020 \cdot$ ISSN 2179-5487 
O mais triste é que não vemos uma articulação de estudantes com professores e membros da comunidade no sentido de reverter essa situação. Há desconhecimento total por parte das organizações de estudantes e conivência de muitos professores e membros da administração da USP. Contudo, é importante reafirmar que estamos sofrendo um ataque implacável desferido por um governo que está sob o comando de um neofascista. Trata-se da extinção de uma forma de ver a produção intelectual e cultural, de um modelo de universidade forjado nos pressupostos de ensino laico e na valorização dos saberes. Essa articulação é imprescindível para que a comunidade universitária reúna forças a fim de resistir a esse poderoso ataque. Caso contrário, mergulharemos, definitivamente, em um retrocesso histórico nunca visto.

\section{RAN}

Em seu doutoramento, pelo que entendi, você investiga os arquivos administrativos da Universidade nos anos 1970 e início da década de 1980. O que esses arquivos revelam sobre a presença da censura nos campi da USP?

\section{MBP}

Meu trabalho é reconstituir os documentos da AESI-USP (Assessoria Especial de Segurança e Informação) para entregá-los aos arquivos da Universidade. As AESIs foram implementadas pelo governo civil-militar e tinham como alvo as repartições federais. Porém, o reitor da USP, Miguel Reale, em seu segundo mandato como reitor, determinou, em 1972, a formalização de uma AESI no campus, em consonância com as diretrizes do SNI. A medida comprometia a própria autonomia da instituição, já que as decisões administrativas de seu órgão máximo, o Conselho Universitário, passaram a subordinar-se a instâncias ligadas ao governo federal. Vários funcionários foram contratados ou transferidos de outras unidades para nele atuar com atribuições diversas. Tais atividades geraram, naturalmente, ao longo desses dez anos de funcionamento, um grande volume de documentos. Mas nada restou do arquivo acumulado pela AESIUSP, que, de acordo com as declarações do ex-reitor Antonio Hélio Guerra Vieira, foi destruído no início de sua gestão (1982-1986). Segundo depoimento que prestou à Comissão da Verdade da USP, em 2013, a decisão de "queimar tudo" foi partilhada com Humberto Marques Filgueiras, chefe da Consultoria Jurídica, e Sérgio Baptista Zaccarelli, coordenador de Administração Geral (Codage), e devidamente registrada em 


\section{REVISTA ANGELUS NOVUS}

ata assinada por eles. É muito reveladora a maneira como o ex-reitor descreve como foram queimados os arquivos. Segundo ele "mandei queimar na Faculdade de Veterinária, onde se incineram os cães”.

Tudo leva a crer que a destruição do arquivo corresponde ao propósito de não deixar vestígios das atividades desenvolvidas pela AESI-USP. O fato é que, não tivesse sido destruído, o arquivo da AESI-USP, para além de inegável valor expiatório, seria também fundamental fonte de conhecimento retrospectivo, capaz de iluminar um dos períodos mais controvertidos da história da Universidade.

Através deles podemos verificar como foi a atuação conivente dos ex-reitores com esse dispositivo. $\mathrm{O}$ que nos leva a examinar a herança deixada por eles no tocante ao assunto autonomia universitária. Exemplo disso foi a admissão através de ato assinado pelo reitor Orlando Marques de Paiva, do general João Franco Pontes para exercer o cargo de chefe da AESI até então ocupado por Krikor Tcherkesian, em 1976. João Franco Pontes, ligado ao General Figueiredo e a militares franceses como Paul Aussarresses. É importante citar essa ligação com o general francês, pois segundo declarações do próprio Aussaresses, em entrevista concedida pouco antes de morrer, ele ensinou aos brasileiros como se ajuda a "suicidar" um preso político, se referindo ao assassinato de Vladimir Herzog. O general João Franco Pontes manteve-se no comando da AESI/USP até a sua extinção, em 1982, na gestão do reitor Antonio Hélio Guerra Vieira, aquele que "incinerou os documentos" por não os considerar tão importantes assim. Embora contratado por Orlando Marques de Paiva, o general Pontes tinha seu salário pago pela CESP. E, segundo Antonio Hélio Guerra Vieira, foi para onde retornou após 1982. Ao estudar estes documentos, inevitavelmente, somos levados ao exame da história imediatamente anterior. O resultado é o questionamento: já houve autonomia universitária na Universidade de São Paulo? A USP esteve sob o comando de Linneu Prestes, que se declarava orgulhoso em repassar nomes de professores e estudantes comunistas ao DOPS; Ernesto Leme, cujo currículo como reitor ostenta o fato de não ter contratado Oscar Niemeyer para lecionar na FAU por ser comunista; Miguel Reale por duas vezes reitor, integralista e colaborador com os serviços de informação implementou a AESI/USP; Luís Antônio da Gama e Silva, Ministro da Justiça da ditadura civil-militar; e outros menos notórios como Orlando Marques de Paiva que contratou o general Pontes e Antonio Hélio Guerra Vieira, o incinerador de documentos. Todos comprovam a total conivência com a falta de autonomia administrativa, de cátedra e financeira da Universidade de São Paulo.

Mesmo decorridos quase 50 anos da implantação desse órgão de controle, que decidia acima de todas as instâncias da universidade e apesar de inúmeras denúncias de

$92 \cdot$ ano XI, n. I6, $2020 \bullet$ ISSN 2I79-5487 
sua existência, oficialmente a USP não faz menção alguma à sua existência e, sobretudo, aos inúmeros prejuízos causados por dez anos de atuação dentro da universidade, ferindo os direitos básicos de autodeterminação.

\section{RAN}

Você faz parte da Equipe Editorial da Revista Angelus Novus e atua profissionalmente no mercado editorial. Como foi sua inserção no mercado editorial e qual o perfil das publicações nas quais trabalhou?

\section{MBP}

Depois de seis anos militando profissionalmente, eu e meu companheiro Ronaldo Almeida, também militante, tínhamos muita dificuldade em nos inserir no mercado de trabalho. Então, como quem não sabe fazer nada vai para a área de comunicação (brincadeira). Passei por algumas agências de publicidade, nos cursos de comunicação e publicidade do SENAC, editoras como Abril, Editora Três. Ronaldo trabalhou na Folha de São Paulo. Depois de um tempo fora do país, nós saímos por um ano em 1985 na contramão da volta dos exilados. Nossos contatos nos levaram a fazer News Letters, House Organs e assim entramos no mercado de revistas técnicas. $\mathrm{Na}$ verdade, comunicação era o que sabíamos fazer, e escrever sempre foi uma consequência disso. ${ }^{2}$

2 Para saber mais sobre a questão da censura na Universidade de São Paulo acessar: «https://sites.usp.br/comissaodaverdade/»; «https://www.adusp.org.br/files/cadernos/livronegro.pdf». 